\title{
Study on the Influence of Power Balance on the Effectiveness of Internal Control in the Listed Company of Energy Industry in China
}

\author{
Yunchen Wang \\ School of Management \\ Sichuan Agricultural University \\ Chengdu, China \\ E-mail:wangyc8684@qq.com
}

Yumei Chen

School of Management

Sichuan Agricultural University

Chengdu, China

Email: chenyumei121647@163.com

\author{
Xuan $\mathrm{Yu}$ \\ Business School \\ Sichuan University \\ Chengdu, China \\ E-mail:yuxuan_0917@aliyun.com \\ Corresponding Author
}

\begin{abstract}
The collapse of China Aviation Oil (Singapore), which has aroused huge attention and consideration on the effective implement of internal control in energy enterprises, warn us that the internal system, lacking the balance of power, will inevitably be an empty talk. This study, based on a series of reality settings such as Operation Guidance for the Internal Control of Petroleum and Petrochemical Industry, has taken the listed companies in energy industry as research samples, and analyzed the influence of power balance on the effectiveness of internal control. The study has found that: (1) Generally, the effectiveness of internal control in energy industry lies above the average level; (2) The power balance, no matter the proxy variable is CEO duality or the proportion of the first big shareholder and the second big shareholder, is negatively correlated with internal control. The research results show that the unbalanced internal power, including both the unbalanced authorities and equity imbalance, in energy industry will weaken the effectiveness of internal control. Hence, to enhance the effectiveness energy enterprises' internal control asks for further optimizing the balance of stock and strengthening the constraint of senior executives' power.
\end{abstract}

Keywords-energy enterprise; effectiveness of internal control; equity structure; duality separation

\section{INTRODUCTION}

Energy industry, being capital and technology intensive industry, is the base and support of national economy. As the critical component of energy industry, the enterprise's risk control ability directly affects the development. Therefore, in order to accelerating the complete of corporate governance, regulating the management and enhancing general control, the internal control in China has made continual progress since 2008, and it has gradually formed the internal control regulation system, based on the Basic Standard for Enterprise Internal Control and auxiliary guidelines, which has kept consistent with international COSO internal control framework [1]. Besides, considering the direct influence of petroleum - the main energy in the world, the petroleum and petrochemical industry also shoulder the responsibility to ensure national energy security and to instil energy to economic development. In 2013, so as to promoting the effective implement of internal control system, the ministry of finance also made the Operation Guidance for the Internal Control of Petroleum and Petrochemical Industry [2].Since then, the energy industry in China has basically established the internal control construction and the implement of security system.

In fact, the effectiveness of enterprise internal control concentratedly reflects its internal control system and its executive capacity which is the key to the effectiveness. According to Basic Standard for Enterprise Internal Control [3], the board of directors is in charge of the built, complete and effective implement of internal control, while the managers are responsible for organizing and leading the daily operation of internal control. Besides, the establishment and implement of enterprise internal control should follow the balance principal and clarify the obligations like decision-making, executions and supervision, forming scientific divisions and counterbalance, especially the balance of power. However, in 2004, the collapses of China Aviation Oil (Singapore) proved that without effective constraint and balance of power, even with the most perfect Risk Management Manual, the enterprise internal control will still fall as an empty work. It is analyzed in Operation Guidance for the Internal Control of Petroleum and Petrochemical Industry that there is serous insider control in China Aviation Oil (Singapore), which means that the whole company is under the control of Chen Jiulin - the executive director, president as well as CEO. Therefore, whether the unbalanced power will weaken enterprise internal control effectiveness? What's the difference of the different balanced power?

Given the establishment and execution situation of internal control system including Operation Guidance for 
the Internal Control of Petroleum and Petrochemical Industry, this study will take the listed companies in energy industry as research samples and analyze the influence of power balance on the effectiveness of internal control. Comparing with the previous researches, the main conclusions and contributions of this study including: (1)This study takes the leading role to evaluate enterprise power balance from the two dimensions of equity structure and duality separation and has discovered that no matter which one lose balance will cause the decrease of the effectiveness of the internal control; (2) This study, sticking closely to the current background and industry features, has provided direct evidence to support the practice of Operation Guidance for the Internal Control of Petroleum and Petrochemical Industry, and has set an example to other industries to strengthen internal control system, and meanwhile it has offered a theory guide to complete equity restriction and also to strengthen power balance.

\section{THEORETICAL ANALYSIS AND RESEARCH HYPOTHESES}

The balance principal of enterprise internal control emphasizes that enterprise should restrict and counterbalance such aspects as governance structure, organizations setup and obligation allocation. Especially like the large energy industry where there are sophisticated hierarchy and complicated institutions, the enterprises are more obliged to organize scientifically and set up appropriate rights and liabilities allocation system as well as necessary power balance system, avoiding arbitrariness. As for the collapses of China Aviation Oil (Singapore), Chen Zhongyang [4] regarded that if the senior leaders exceeded authority, the whole internal control and risk management system would lose their efficiency. Therefore, power balance should be adopted in equity structure and duality so as to ensure the efficiency of internal control and avoid the malfunctions.

Duality separation and the effectiveness of internal control. Whether there is clear clarification of board of directors and managers' responsibility and whether they are counterbalanced are the core benchmarks to measure the effectiveness of internal control. Being the general manager as well as the chairman at the same time needs self supervision. The agent theory pointed out that human beings are rational self-interests and opportunists, and the senior managers cannot try their best to serve shareholders [5]. The combined title of board chair and CEO will enlarge the risk of decision making and sabotage internal control system with concentrated power [6]. Moreover, it has made it clear in Operation Guidance for the Internal Control of Petroleum and Petrochemical Industry that the main risks existing in such businesses as overseas business boil down to the unappropriated responsibilities and rights allocation as well as unbalanced power, which cause the business operation losing control. Base on the analysis above, this study poses the hypothesis 1: under the premise of the same condition, compared with the separation of board of directors and general manager, the CEO duality will obviously weaken the effectiveness of enterprise internal control.

Equity restriction and the effectiveness of internal control. Equity restriction refers to that more than two big shareholders co-control the company, reflecting the counterbalance between the big shareholders, which is a special equity structure and also a restrict governing mechanism [7, 8]. However, the establishment and implement of internal control system is based on the establishment of internal environment, especially the environment management. The Operation Guidance for the Internal Control of Petroleum and Petrochemical Industry also required clearly that the relevant enterprises should study the big international petroleum companies, establishing normative cooperate governance structure containing equity restriction and other systems. According to the exiting researches, equity restriction could constraint dominant stockholders, decrease the agency cost of shareholders and insider control and thus enhance the effectiveness of internal control and boost enterprise value $[9,10,11,12]$. Nonetheless, if the largest shareholder over control stock rights, the governance structure will lose balance and the big shareholder will lack restraint, which create great opportunities to make private interests. And eventually it will reduce the effectiveness of internal control until it falls as an empty form [13]. Referring to the previous analysis, this study put forward the hypothesis 2: the equity balance degree measured by the proportion of the first big shareholder and the second big shareholder is in a negative correlation with the enterprise internal control.

\section{III.RESEARCH DESIGN}

\section{A. Sample selection and data sources}

Consulting the About the Classification of China Securities released by China Securities Index Co.,Ltd, the Shanghai energy industry index constitute stock list, the industry classification standard of listed company made by CSRC and the samples used in Zhou Guodong [14], this study selected the listed companies of energy industry as researching samples and also took the Basic Standard for Enterprise Internal Control and its auxiliary guidelines into consideration. Considering "the enterprise basic internal control norms" is published in 2008, the samples selected in this study are all non-financial A-share listed companies from 2008 to 2012. After eliminating ST or PT and companies whose data is seriously missed, finally there remain 188 samples. In addition, "The Chinese listed company internal control index" comes from Shenzhen DI BO enterprise risk management technology co., LTD., and the rest data is from CSMAR database.

Proxy variables reflecting the effectiveness of internal control. According to the interpretation of the enterprise internal control evaluation guide-lines by the accounting department the of ministry of finance and, the effectiveness of internal control refers to the reasonable assurance that the establishment and implementation of enterprise internal control provide for the achievement of controlling objectives. Thus it can be seen that the effectiveness of the internal control system can be measured by the achieving situation of internal control strategies, management, reports, compliance and assets security [15]. "DI BO · The Chinese listed company internal control index" launched by Shenzhen DI BO enterprise risk management technology co., LTD covers the execution results of the enterprise strategy (market share and risk coefficient), return (return rate and net 
profit margin of invested capital), the authenticity and integrity of information disclosure (the audit opinions and the financial restatement), the compliance legality (laws and regulations violation as well as lawsuit), asset security (asset value maintenance and improvement).It also supplies and corrects the defects of internal control. In fact, this index reflects the main part of enterprise internal control goals, and it is also the manifestation of effective implementation of the internal control. Therefore, we should choose this index as the proxy variable to reflect the effectiveness of internal control.

\section{B. Test model and illustration of relevant variables}

In order to test the hypotheses, we have established the following model (1).

$$
\begin{aligned}
I C_{i t}= & \beta_{0}+\beta_{1} X_{i t}+\beta_{2} I N D R A_{i t}+\beta_{3} L E V_{i t} \\
& +\beta_{4} E P S_{i t}+\beta_{5} \text { GROW }_{i t}+\sum Y E A R_{i t}+\varepsilon_{i t}
\end{aligned}
$$

Among them, the dependent variable is IC, reflecting the effectiveness of enterprise internal control. The higher the index is, the more effective the internal control will be. The independent variable is the power balance. The combination of general manager and CEO will be noted as 1 represents the opposite. The higher the value is, the weaker the restriction will be. The ZHSHA is measured by the proportion of the first big shareholder and the second big shareholder. The higher the value is, the lower the equity restriction will be. Besides, referring to the researches of Doyle et al.[16], Liu Qiliang [17], Lu Dong [18], we also control the factors like INDRA, LEV, EPS and GROW to reflect finance and governance issues. The definitions of main variables are seen in table I.

TABLE I. THE DEFINITIONS OF MAIN VARIABLES

\begin{tabular}{|c|c|l|}
\hline Variable & Symbol & \multicolumn{1}{|c|}{ Variable Definition } \\
\hline $\begin{array}{c}\text { Dependent } \\
\text { Variable }\end{array}$ & IC & $\begin{array}{l}\text { Reflected by the effectiveness of IC, standardized by } \\
\text { dividing the DI BO, China listed company internal } \\
\text { control index with 100. }\end{array}$ \\
\hline \multirow{3}{*}{$\begin{array}{c}\text { Independent } \\
\text { Variable }\end{array}$} & DUAL & $\begin{array}{l}\text { 1 represents the combination of general manager and } \\
\text { the chairman of the board; 0stands the opposite. }\end{array}$ \\
\cline { 2 - 3 } & ZHSHA & $\begin{array}{l}\text { The proportion of first shareholder and second } \\
\text { shareholder. }\end{array}$ \\
\hline \multirow{4}{*}{$\begin{array}{c}\text { Control } \\
\text { Variable }\end{array}$} & INDRA & $\begin{array}{l}\text { Independent director number/the number of the board } \\
\text { of directors. }\end{array}$ \\
\cline { 2 - 3 } & LEV & Asset-liability ratio. \\
\cline { 2 - 3 } & EPS & Earnings/ Total share \\
\cline { 2 - 3 } & GROW & (Current year profit - Initial profit)/ Initial profit. \\
\hline
\end{tabular}

\section{IV.TEST RESULTS AND ANALYSES}

\section{A. Descriptive statistics}

TABLE II. THE DESCRIPTIVE STATISTICS OF MAIN VARIABLES

\begin{tabular}{|c|c|c|c|c|c|c|}
\hline Variable & $\mathbf{N}$ & Mean & SD & Median & Min & Max \\
\hline IC & 188 & 6.9711 & 1.0994 & 6.9362 & 1.7006 & 9.9536 \\
\hline DUAL & 188 & 0.1064 & 0.3092 & 0.0000 & 0.0000 & 1.0000 \\
\hline ZHSHA & 188 & 26.2682 & 35.2577 & 13.9413 & 1.0717 & 220.7067 \\
\hline INDRA & 188 & 0.3630 & 0.0556 & 0.3333 & 0.2727 & 0.7143 \\
\hline LEV & 188 & 0.4851 & 0.1754 & 0.5007 & 0.0071 & 0.8868 \\
\hline EPS & 188 & 0.7326 & 0.8135 & 0.6427 & -2.2501 & 3.2421 \\
\hline GROW & 188 & 0.6267 & 2.9940 & 0.2026 & -0.4923 & 38.1197 \\
\hline
\end{tabular}

The descriptive statistics of the main variables are seen in table II. In this study, the power balance of one company is evaluated by DUAL and ZHSHA. To be specific, the mean level of DUAL is 0.1064 ; the SD is 0.3092 ; the Max is 1 . The Mean of DUAL is 26.2682, The $\mathrm{SD}$ is 35.2577 and the Max is 220.7067. The research results showed that the energy industry has lost the balance of power to a certain degree. In addition, as to the effectiveness of internal control, the mean of IC is 6.9711; the SD is 1.0994, and the Max is 9.9536 of 10 . This indicates that internal control in listed company of energy industry lies above the average. Furthermore, we also calculated the VIF of the main variables, which are all below 2, implying that this model does not exist serious multicollinearities.

TABLE III. ANALYSIS OF PEARSON CORRELATION COEFFICIENT

TABLE III. ANALYSIS OF PEARSON CORRELATION COEFFICIENT
\begin{tabular}{|c|c|c|c|c|c|c|c|}
\hline Variable & $\mathbf{1}$ & $\mathbf{2}$ & $\mathbf{3}$ & $\mathbf{4}$ & $\mathbf{5}$ & $\mathbf{6}$ & $\mathbf{7}$ \\
\hline IC & 1 & & & & & & \\
\hline DUAL & $-0.173^{* *}$ & 1 & & & & & \\
\hline ZHSHA & $-0.112^{* *}$ & 0.120 & 1 & & & & \\
\hline INDRA & -0.033 & $-0.124^{*}$ & $0.142^{*}$ & 1 & & & \\
\hline LEV & -0.064 & $-0.145^{* *}$ & 0.039 & -0.005 & 1 & & \\
\hline EPS & $0.365^{* *}$ & $-0.164^{* *}$ & 0.019 & -0.060 & $-0.163^{* *}$ & 1 & \\
\hline GROW & 0.049 & -0.065 & 0.0003 & -0.025 & 0.079 & $0.12^{*}$ & 1 \\
\hline
\end{tabular}
Note: ${ }^{* *},{ }^{* *},{ }^{*}$ Significant at $1 \%, 5 \%$, and $10 \%$ levels, respectively.

The analysis results of the main variables' Pearson correlation coefficient are listed in the table III. The correlation coefficient of IC and DUAL is -0.173 and the significance level is $5 \%$, manifesting that the CEO duality of the listed company of energy industry will lower the effectiveness of internal control. The correlation coefficient of IC and ZHSHA is -0.112 and the significance level is $5 \%$, indicating that the unbalanced power of the listed company of energy industry will reduce the effectiveness of internal control. Generally speaking, the comprehensive correlation coefficients are below 0.4, demonstrate that there are no serious multicollinearities. Followly, this study will control other relevant variables and do further multiple regression analyses to test the hypothesis.

\section{B. Regression analysis}

Seen in table IV, we made an estimation of model one, analyzing the influences of different power balances degree on the internal control. In regression 1 , the regression coefficient of DUAL is -0.4532 (the significance level is $10 \%$ ), indicating that comparing with the separation of general manager and CEO, the CEO duality the significantly decrease the effectiveness of enterprise internal control, which proved the hypothesis one.

TABLE IV. TEST ON THE EFFECTIVENESS OF POWER BALANCE

\begin{tabular}{|c|c|c|c|c|}
\hline \multicolumn{5}{|c|}{ Dependent variable :IC } \\
\hline \multirow{3}{*}{ Variable } & \multicolumn{4}{|c|}{ Total samples } \\
\hline & \multicolumn{2}{|c|}{ regression 1} & \multicolumn{2}{|c|}{ regression 2} \\
\hline & Coefficient & T value & Coefficient & T value \\
\hline DUAL & $-0.4532^{*}$ & -1.7582 & & \\
\hline ZHSHA & & & $-0.0039^{* *}$ & -2.2341 \\
\hline INDRA & -0.6088 & -0.4907 & 0.0908 & 0.0795 \\
\hline LEV & -0.1447 & -0.4466 & 0.0292 & 0.0927 \\
\hline EPS & $0.4486^{* * * *}$ & 6.0912 & $0.4895^{* * * *}$ & 6.5281 \\
\hline GROW & -0.0035 & -0.2549 & -0.0023 & -0.1628 \\
\hline CONS & $6.8835^{* * *}$ & 13.099 & $6.5590^{* * *}$ & 13.1864 \\
\hline YEAR & \multicolumn{2}{|c|}{ control } & \multicolumn{2}{|c|}{ control } \\
\hline $\mathrm{R}^{2}$ & \multicolumn{2}{|c|}{0.1575} & \multicolumn{2}{|c|}{0.1575} \\
\hline $\mathrm{F}$ & \multicolumn{2}{|c|}{$6.85^{* * *}$} & \multicolumn{2}{|c|}{$7.21 * * *$} \\
\hline OBS & \multicolumn{2}{|c|}{188} & \multicolumn{2}{|c|}{188} \\
\hline
\end{tabular}

AND INTERNAL CONTROL: BASE ON DIFFERENT EVALUATIONS 
In the regression 2, the regression coefficient of ZHSHA is below zero (the significance level is 5\%), showing that the power balance whose the proxy variable is the proportion of the first big shareholder and the second big shareholder, is in a negative correlation with enterprise internal control. The higher the proportion value is, the worse the internal control will be, which in turn proved the hypothesis two.

\section{ROBUST TESTS}

Considering the potential negative influence of extreme value in variables and the limitation of samples, this study has $0.5 \%$ of Winsorize on each variable and has redone multiple regression analysis. The results still stay the same. Given that there may be endogenous problems between power balance level and in ternal control efficient, the model (1)was improved by repeating the tests on hypothesis 1 and hypothesis 2 , and e xamining the influence of the level of power balance (both the L_DUAL and L_ZHSHA) in last year on the effectiv eness of internal control in this year. The testing results tu rned out to be unchanged, demonstrating that

the tests on hypothesis 1 and hypothesis 2 are stable and st eady.

\section{VI.RESEARCH CONCLUSION AND ENLIGHTENMENT}

In 2004, the collapse of China Aviation Oil (Singapore), which have aroused huge attention and consideration on the effective implement of internal control in energy enterprises, warns us that the internal system, lacking the balance of power, will inevitably be an empty talk. Under the background of the series of enterprise internal control systems since 2008, this study has taken the listed companies in energy industry as research samples and analyzed the influence of power balance on the effectiveness of internal control. The research results suggest that (1) in energy industry, the mean of the effectiveness of internal control is 6.9711 of 10 , which is above the average level; (2) The power balance, no matter the proxy variable is CEO duality or the proportion of the first big shareholder and the second big shareholder, is in inverse proportion to enterprise internal control.

This study gave a lesson that simply relying on the self-restraint and self-control can hardly improve the effectiveness of internal control in energy industry. Only the considerate governance thoughts and system arrangement corresponding to the modern companies could enhance internal control, which means avoiding all unbalanced phenomena of concentrated power and meanwhile defining the rights between CEO and general manager, ensuring the separation of supervision right and business operations.

In conclusion, this study took the leading role to combine the current background of internal control and to study the repercussions of power control on internal control. The research results have provided direct evidence to support the practice of Operation Guidance for the Internal Control of Petroleum and Petrochemical Industry, and have set an example to other industries to strengthen internal control system, and meanwhile they has offered a theory guide to complete equity restriction and to strengthen power balance.

\section{ACKNOWLEDGEMENTS}

We are deeply grateful for the support from the Humanities \& Social Sciences Research Fund of the Ministry of Education: the effectiveness of internal control in state-owned enterprises based on the angle of political connection and CEO incentive (project approval number: 14YJC630135) and the support from the 2014 Annual Project of Sichuan Agricultural University German Research Center of Sichuan Philosophy Society and Science Key Research Base (project approval number: ZDF1404).

\section{REFERENCES}

[1] J. Wang, "Release and implement internal control regulation, serve the development of economic society," Chinese Accounting Newspaper, 2010, in press.

[2] The Accounting Department of the Ministry of Finance, Operation Guidance for the Internal Control of Petroleum and Petrochemical Industry, 2013.

[3] The Accounting Department of the Ministry of Finance, the Explanation Basic Standard for Enterprise Internal Control, Economic Science Press, 2010.

[4] Z. Y. Chen, "The useless unbalanced risk control mechanism," China Securities Journal, vol.12, 2004.

[5] S. M. Chen, R. Yi and T. X. Hui, "R\&D strength and corporate value - the moderating function of equity and CEO duality," Studies in Science of Science, vol.3, 2012, pp.441-448.

[6] M.C. Jensen, "The modern industrial revolution, exit, and the failure of internal control systems," The Journal of Finance, vol.7, 1993, pp.831-880.

[7] M. Faccio and L.H.P. Lang, "The ultimate ownership of western European corporations," Journal of Financial Economics, vol.65 (3), 2002, pp.365-395.

[8] Z. J. Chen, P. Xu and G. Y. Bai, "The research of the relation between equity restriction of listed company and corporate performance in the angle of dynamic competition," Foreign Economics and Management, vol.11, 2014, pp.3-11.

[9] M. Bennedsen, M. Fosgerau, and K. Nielsen, "The strategic choice of control allocation and ownership distribution in closely held corporations," Working Paper, Copenhagen Business School, 2003.

[10] X. Y. Chen and H. Wang, "Equity restriction and corporate value: model and empirical evidence," The Journal of Quantitative and Technical Economics, vol.11, 2004, pp.102-110.

[11] Y. Q. Li and J. L. Yu., "Equity restriction and the effectiveness of internal control-based on the cases study of wine making listed company from 2008 to 2010," Accounting Research, vol.2, 2012, pp.50-56.

[12] D. Lu, Y. Y. Li, D. Yang and J. J. Yang, "Government control right, equity restriction and corporate value - based on empirical evidence of state-owned listed company," Public Finance Research, vol.1, 2012,pp.71-74.

[13] Y. X. Li, "Equity balance, effectiveness of internal control and corporate performance," The Chinese Certified Public Accountant, vol.10, 2013, pp.57-62.

[14] G. D. Zhou, "Analysis of energy industry tax influence in our country," Soft Science, vol.4, 2012, pp.127-130.

[15] Chinese listed company internal control index research group, Chinese listed company internal control index research, Accounting Research, vol.12, 2011, pp.20-24.

[16] J. Doyle, W.L.W. Ge, and S. McVay, "Determinants of weaknesses in internal control over financial reporting," Journal of Accounting and Economics, vol.44 (1-2), 2007, pp.193 -223.

[17] Q. L. Liu, L. Luo, W. F. He and H. W. Chen, "Property Right, institutional environment and internal control," Accounting Research,vol.3,2012, pp.52-61.

[18] D. Lu, Y. C. Wang and P. Fu, "Does CEO motivation enhance the effectiveness of internal control?--the empirical evidence from state-owned listed company," Accounting Research, col.6, 2014, pp.66-72. 